\title{
Uji Eksperimental Stabilisasi Tanah Lempung Dengan Menggunakan Pasir Dan Kapur
}

\author{
Prasetya Adi Putra ${ }^{1}$, Wilis Sutiono ${ }^{2}$, Rokhman $^{2}$ \\ Program Studi Teknik Sipil Universitas Muhammadiyah Sorong \\ Jl. Pendidikan No 27,Kota Sorong 98400 \\ Email : tekniksipilsorong@gmail.com
}

\begin{abstract}
ABSTRAK
Tanah yang memiliki daya dukung yang tinggi sangat diperlukan dalam pembangunan suatu konstruksi. Sifat tanah dengan daya dukung yang rendah dapat diperbaiki dengan perbaikan tanah. Seperti halnya di daerah Kabupaten Sorong, karakteristik tanah di wilayah tersebut mayoritas tergolong tekstur halus. Salah satu metode yang banyak dilakukan adalah metode stabilisasi, yaitu stabilisasi dengan menggunakan bahan additive. Pada penelitian ini digunakan bahan additive berupa pasir dan kapur yang diharapkan untuk mengetahui seberapa besar pengaruhnya pada nilai CBR tanah lempung. Pengujian tanah meliputi sifat fisik dan mekanik, dengan menggunakan variasi penambahan pasir $20 \%$ pada setiap penambahan kapur 4\%, 8\%, 12\% dan 16\% dari berat sampel tanah. Penggunaan campuran pasir dan kapur dapat memperbaiki sifat fisik dan mekanik tanah lempung. Pada pengujian fisik seperti batas-batas Atterberg, Indek Plastisitas mengalami penurunan setelah distabilisasi, sementara pada pengujian mekanik CBR (unsoaked) tanah asli sebesar 15,76\%, naik pada pencampuran kadar pasir 20\% + kapur 4\% dengan waktu pemeraman 7 hari sebesar $16,58 \%$. Nilai CBR mengalami penurunan pada penambahan pasir $20 \%+$ kapur $8 \%, 12 \%$ dan $16 \%$.
\end{abstract}

Kata kunci : CBR (California Bearing Ratio), Pasir dan Kapur, Stabilisasi Tanah, Tanah Lempung

\section{PENDAHULUAN}

Pemerintah Kabupaten Sorong (2014), Kabupaten Sorong memiliki luas wilayah 13.603,46 kilometer persegi dengan luas lautan 514,65 kilometer pesegi dan luas daratan 845,71 kilometer persegi. Kabupaten Sorong termasuk salah satu kabupaten yang cukup pesat dalam hal perkembangan di Provinsi Papua Barat, baik perkembangan infrastruktur seperti jalan, perumahan, dan kawasan komersil lainnya. Kondisi umum jaringan jalan di Kabupaten Sorong beberapa tahun terakhir terus mengalami penurunan. Beberapa sebab utama adalah kualitas konstruksi jalan yang belum optimal, pembebanan yang berlebihan, daya dukung tanah yang rendah, bencana alam seperti longsor, banjir, dan gempa bumi. Dengan melihat kondisi umum jaringan jalan tersebut maka pembangunan jalan perlu ditingkatkan.

Karakteristik tanah di Kabupaten Sorong terdiri dari tekstur halus, sedang, kasar, dan gambut. Mayoritas tanah di wilayah Kabupaten Sorong memiliki tekstur halus. Ukuran butir tanah halus yaitu kurang dari $0,002 \mathrm{~mm}$, tanah ini biasa di sebut dengan tanah lempung. Berdasarkan sifat yang dimiliki, tanah lempung pada umumnya dikategorikan material tanah dasar (subgrade) yang buruk. Untuk meningkatkan daya dukung tanah lempung tersebut digunakan metode perbaikan tanah yang pada masa ini adalah metode stabilisasi.

Hardiyatmo, H.C (2010), dalam pengertian luas yang dimaksud stabilisasi adalah pencampuran tanah dengan bahan tertentu, guna memperbaiki sifat-sifat tanah, atau dapat pula stabilisasi tanah adalah usaha untuk merubah atau memperbaiki sifat-sifat teknis tanah agar memenuhi syarat teknis tertentu. Proses stabilisasi tanah meliputi pencampuran tanah dengan tanah lain untuk memperoleh gradasi yang diinginkan, atau pencampuran tanah dengan bahan-bahan buatan pabrik, sehingga sifat-sifat teknis tanah menjadi lebih baik. Untuk merubah sifat-sifat teknis tanah maka dapat dilakukan dengan cara penanganan dari yang paling mudah, seperti pemadatan sampai teknik yang lebih mahal seperti pencampuran pasir dan kapur. Penambahan pasir dan kapur ke dalam tanah lempung akan memperbaiki sifat tanah dengan menurunkan tingkat plastisitas tanah dan akan merubah kapasitas daya dukungnya.

Dalam penelitian ini akan dijelaskan seberapa besar pengaruh campuran pasir dan kapur untuk stabilisasi tanah lempung, serta perubahan daya dukungnya setelah dicampur dengan pasir dan kapur.

Tujuan merupakan hal terpenting dari suatu penelitian agar peneliti dapat mengarahkan 
maksud dari penelitiannya. Tujuan dari penelitian ini adalah Mengidentifikasi seberapa besar pengaruh pasir dan kapur terhadap nilai CBR tanah

\section{Metode}

\subsection{Lokasi Pengambilan Sampel Tanah}

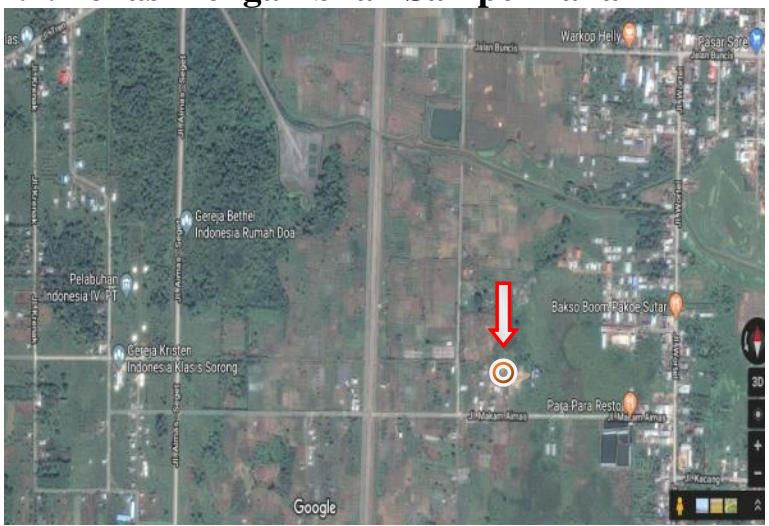

Gambar 1. Peta Daerah Jalan Makam, Kelurahan Malasom, Distrik Aimas, Kabupaten Sorong

Sampel tanah yang akan diuji adalah jenis tanah lempung, yang diambil dari Daerah Jalan Makam, Kelurahan Malasom, Distrik Aimas, Kabupaten Sorong. Sampel tanah yang diambil adalah sampel tanah terganggu (distributed soil).

\subsection{Lokasi dan Waktu Penelitian}

Penelitian dilakukan di Laboratorium Mekanika Tanah Universitas Muhammadiyah Sorong. Waktu Penelitian dimulai pada tanggal 10 mei sampai dengan tanggal 20 juli 2018.

\subsection{Bahan dan Alat Uji}

1. Bahan yang digunakan dalam penelitian dilaboratorium adalah :

a. Tanah lempung yang diambil sampel tanahnya dari Daerah Jalan Makam, Kelurahan Malasom, Distrik Aimas, Kabupaten Sorong

b. Pasir yang diambil dari daerah Kelurahan Malanu, Distrik Sorong Utara, Kota Sorong

c. Kapur alami yang diambil dari pegunungan Kampung unggih, Distrik Wayer, Sorong Selatan

2. Alat yang digunakan dalam penelitian dilaboratorium :

a. Tabung silinder (mold) berdiameter 15 $\mathrm{cm}$ (6 inch) dengan volume $2837 \mathrm{~cm}^{3}$ $\left(1 / 10 \mathrm{ft}^{3}\right)$ yang dilengkapi dengan alas dan tabung tambahan di bagian atas yang disebut collar

b. Alat Penggoyang

c. Penumbuk (hammer) berat $10 \mathrm{lbs}$ (sekitar $4.5 \mathrm{~kg}$ )

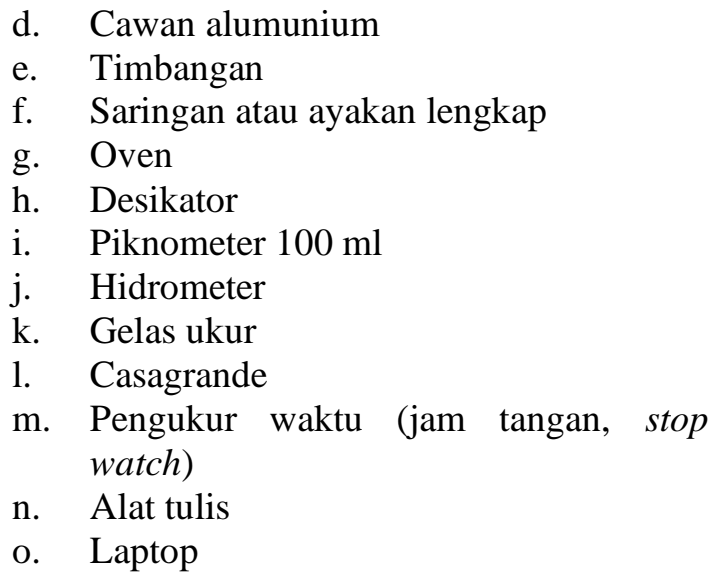

\subsection{Teknik Pengumpulan Data}

Data-data yang digunakan dalam penelitian ini adalah sebagai berikut :

1. Data Primer

Data primer dalam penelitian ini adalah data yang diperoleh dengan pengumpulan langsung dilokasi penelitian. Data primer ini berupa :
a. Kadar Air
b. Berat Jenis
c. Batas-batas Atterberg
d. Analisa Butiran
e. Pemadatan (Compaction)
f. CBR Laboratorium (California Boaring Ratio)

2. Data Sekunder

Data-data sekunder yang digunakan dalam penelitian ini diambil dari referensi-referensi yang berkaitan dengan topik yang sedang dibahas baik melalui penelitian terdahulu, jurnal, buku-buku maupun media elektronik seperti website.

\subsection{Pelaksanaan Pengujian}

Pelaksanaan pengujian dilakukan di Laboratorium Mekanika Tanah, Prodi Teknik Sipil, Fakultas Teknik, Universitas Muhammadiyah Sorong. Pengujian yang dilakukan dibagi menjadi 2 bagian, yaitu pengujian untuk mengetahui sifat fisik tanah dan pengujian CBR tanah dengan campuran pasir dan kapur, adapun pengujian tersebut adalah sebagai berikut :

1. Pengujian Kadar Air

2. Pengujian Berat Jenis (Specific Gravity)

3. Pengujian Atterberg Limit

4. Pengujian Analisa Butiran

5. Pengujian Pemadatan (Compaction)

6. Pengujian Nilai CBR Laboratorium (California Boaring Ratio)

Pada pengujian tanah campuran, setiap kapur sebesar $4 \%, 8 \%, 12 \%$, dan $16 \%$ dan dilakukan pengujian CBR Laboratorium tanpa rendaman (Unsoaked). 


\subsection{Metode Pencampuran Pasir dan Kapur untuk Pengujian CBR}

Metode pencampuran untuk masing-masing persentase pasir dan kapur adalah:

1. Pasir yang telah kering oven kemudian di saring dengan lolos saringan No.4.

2. Kapur yang telah kering oven kemudian di saring dengan lolos saringan No.4.

3. Pasir dan kapur dicampur dengan sampel tanah yang telah ditumbuk (butir aslinya tidak pecah) dan lolos saringan No. 4 (4,75 $\mathrm{mm}$ ) dengan persentase pasir $20 \%$ ditambah kapur 4\%, 8\%, 12\%, dan $16 \%$.

4. Pencampuran dilakukan dengan cara menimbang tanah, pasir, serta kapur sesuai kadar masing-masing pada tiap campuran kemudian mencampurkan ketiga bahan tersebut ke dalam pan besar dengan cara mengaduknya secara perlahan sambil ditambahkan air sedikit demi sedikit sesuai dengan kadar air optimum yang dibutuhkan.

5. Tanah yang sudah tercampur pasir dan kapur siap untuk dipadatkan lalu diperam selama 7 hari, di pastikan agar tidak ada udara yang masuk pada benda uji tersebut.

\subsection{Prosedur Pengujian}

1. Pengujian Kadar Air

Proses penentuan kadar air untuk tanah ditentukan berdasarkan SNI 1965:2008.

2. Pengujian Berat Jenis

Pengujian ini berdasarkan SNI 1964:2008.

3. Pengujian Atterberg Limit

Pengujian atterberg limit meliputi pengujian batas cair (liquit limit) dan batas plastis (plastis limit).

a. Pengujian Batas Cair (liquit limit)

Pengujian ini dilakukan berdasarkan SNI 1967:2008.

b. Pengujian Batas Plastis (Plastic Limit)

Pengujian ini dilakukan berdasarkan SNI 1966:2008.

\section{Pengujian Analisa Butiran}

Pengujian analisa butiran dibagi menjadi dua tahap yaitu uji hydrometer dan analisa saringan. Uji hydrometer bertujuan untuk menentukan pembagian ukuran butiran tanah yang lolos saringan No. 200 sedangkan uji analisa saringan bertujuan untuk menentukan pembagian ukuran butir suatu contoh tanah. Pengujian ini dilakukan berdasarkan SNI 3423:2008.

5. Pengujian Pemadatan

Pengujian ini dilakukan berdasarkan SNI 1743:2008.

6. Pengujian CBR Laboratorium

Pengujian ini dilakukan berdasarkan dan SNI 1744:2012 dan SNI 03-1744-1989.

\subsection{Pengujian Penentuan Jenis Tanah}

Pengujian ini dilakukan untuk memastikan jenis tanah yang digunakan adalah jenis tanah lempung. Dalam pengujian jenis tanah ini dilakukan 2 pengujian dasar, diantaranya yaitu pengujian atterberg limit dan pengujian analisis butiran. Sampel tanah yang di ambil dari daerah Kelurahan Malasom Distrik Aimas Kabupaten Sorong menunjukan jenis tanah berlempung dengan plastisitas tinggi dan jenis tanah ini yang kemudian akan digunakan untuk pengujian selanjutnya.

\section{Hasil Penelitian}

3.1. Hasil Pengujian Sifat Fisik dan Mekanik Tanah Asli

Tabel 1. Hasil Pengujian Sifat Fisik dan Mekanik

\begin{tabular}{clc}
\multicolumn{3}{c}{ Tanah Asli } \\
\hline No & \multicolumn{1}{c}{ Pengujian } & Hasil \\
\hline 1 & Berat Jenis (gr/cm3) & 2,41 \\
2 & Batas Cair (\%) & 64,52 \\
3 & Batas Plastis (\%) & 27,29 \\
4 & Indeks Plastisitas (\%) & 37,23 \\
5 & Lolos Saringan 200 (\%) & 78,50 \\
6 & Kadar Air Optimum (\%) & 21,04 \\
7 & Berat Kering & 1,583 \\
& Maksimum (gr/cm3) & 15,76 \\
\hline & CBR Laboratorium (\%) \\
\hline \multicolumn{2}{c}{ (Sumber : Hasil Laboratorium 2018) }
\end{tabular}

\subsection{Hasil Pengujian Sifat Fisik dan Mekanik Tanah Asli, Pasir dan Kapur}

Hasil uji sifat fisik dan mekaniik campuran tanah lempung dengan semen untuk kadar campuran $5 \%, 10 \%, 15 \%$ dan $20 \%$ dapat dilihat pada tabel 2 . 
Tabel 2. Hasil Pengujian Sifat Fisik dan Mekanik Tanah Asli, Pasir dan Kapur

\begin{tabular}{llccccc}
\hline \multirow{2}{*}{ No } & \multicolumn{1}{c}{ Pengujian } & Tanah Asli & $\begin{array}{c}\text { Pasir 20\% } \\
+\end{array}$ & $\begin{array}{c}\text { Pasir 20\% } \\
+\end{array}$ & $\begin{array}{c}\text { Pasir 20\% } \\
+\end{array}$ & $\begin{array}{c}\text { Pasir 20\% } \\
+\end{array}$ \\
\hline 1 & Kapur 4\% & Kapur 8\% & Kapur 12\% & Kapur 16\% \\
\hline 2 & Batas Cair (\%) & 2,41 & 2,72 & 2,58 & 2,55 & 2,43 \\
3 & Batas Plastis (\%) & 27,52 & 50,70 & 49,06 & 48,02 & 46,40 \\
4 & Indeks Plastisitas (\%) & 37,23 & 23,87 & 23,26 & 22,36 & 21,32 \\
5 & CBR Laboratorium (\%) & 15,76 & 16,58 & 12,54 & 8,91 & 7,95 \\
\hline
\end{tabular}

(Sumber : Hasil Laboratorium 2018)

\section{Pembahasan}

\subsection{Pengujian Tanah Asli}

Hasil pengujian yang dilakukan di Laboratorium Mekanika Tanah Universitas Muhammadiyah Sorong di peroleh data sifat-sifat fisik dan sifat mekanis tanah lempung. Data fisik untuk pengujian yaitu berupa uji berat jenis, batas-batas atterberg dan analisa butiran. Sedangkan data mekanis yaitu berupa uji pemadatan dan CBR Laboratorium.

1. Pengujian Berat Jenis dan Atterberg Limit

Tabel 3. Hasil Pengujian Berat Jenis dan Atterberg Limit

\begin{tabular}{clc}
\hline No & \multicolumn{1}{c}{ Pengujian } & Hasil \\
\hline 1 & Berat Jenis (gr/cm3) & 2,41 \\
2 & Batas Cair (\%) & 64,52 \\
3 & Batas Plastis (\%) & 27,29 \\
4 & Indeks Plastisitas (\%) & 37,23 \\
\hline
\end{tabular}

(Sumber : Hasil Laboratorium 2018)

Dari hasil pengujian laboratorium didapatkan nilai berat jenis sebesar $2,41 \mathrm{gr} / \mathrm{cm}^{3}$, sedangkan untuk pengujian atterberg limit didapatkan nilai batas cair (LL) sebesar $64,52 \%$, nilai batas plastis (PL) sebesar 27,29\%. Sehingga nilai indeks plastisitas (PI) sebesar 37,23\%

2. Pengujian Analisa Butiran

Tabel 4. Hasil Pengujian Analisa Saringan

\begin{tabular}{cccccc}
\hline \multicolumn{2}{c}{ Saringan } & \multicolumn{3}{c}{ Tertahan } & Lolos \\
\hline Nomor & $\begin{array}{c}\varnothing \text { Lubang } \\
(\mathrm{mm})\end{array}$ & $\begin{array}{c}\text { Berat } \\
(\mathrm{gr})\end{array}$ & $\%$ & $\%$ Kumulatif & $\%$ \\
\hline$\# 4$ & 4,75 & - & - & - & 100 \\
$\# 40$ & 2,00 & 0,79 & 1,58 & 1,58 & 98,42 \\
$\# 50$ & 0,850 & 1,36 & 2,72 & 4,30 & 95,70 \\
$\# 60$ & 0,425 & 2,26 & 4,52 & 8,82 & 91,18 \\
$\# 100$ & 0,149 & 3,58 & 7,16 & 15,98 & 84,02 \\
$\# 200$ & 0,075 & 2,76 & 5,52 & 21,50 & 78,50 \\
PAN & - & - & - & - & - \\
\multicolumn{2}{c}{ Berat Total } & 10,75 & & & \\
\hline
\end{tabular}

(Sumber : Hasil Laboratorium 2018)
Dapat dilihat pada tabel hasil pengujian analisa saringan diatas, bahwa tanah yang lolos saringan No.4 (4,75 mm) sebesar $100 \%$, sedangkan tanah yang lolos saringan no.200 $(0,075 \mathrm{~mm})$ sebesar $78,50 \%$.

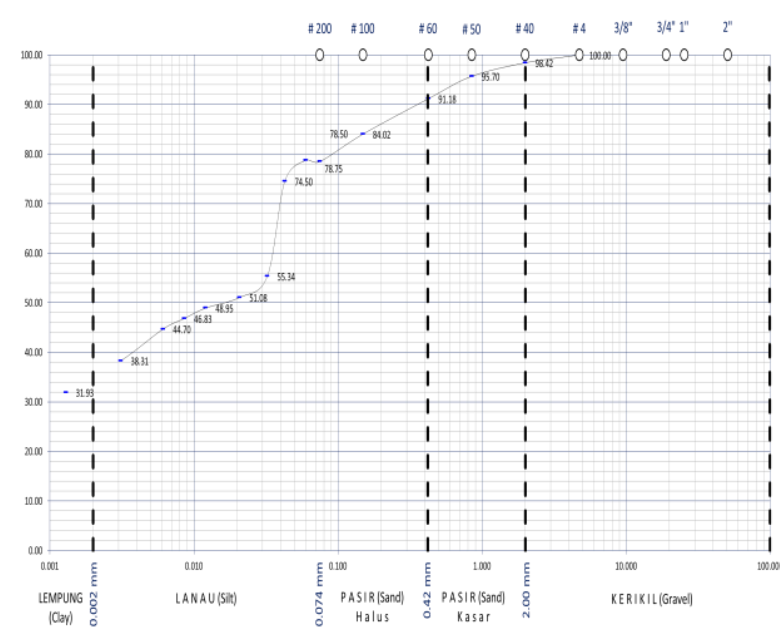

Gambar 2. Grafik Distribusi Ukuran Analisa Butiran Tanah Asli

Dari gambar diatas dapat dilihat, persentase butiran terbesar berada pada kategori lanau, hal ini mungkin terjadi karena tanah yang diambil tercampur dengan tanah urugan yang memiliki kandungan lanau yang lebih besar.

3. Pengujian Pemadatan (Compaction)

Tabel 5. Hasil Pengujian Pemadatan (Compaction)

\begin{tabular}{lccc}
\hline \multicolumn{1}{c}{ Uraian } & I & II & III \\
\hline $\begin{array}{l}\text { Kadar Air } \\
\text { Optimum (\%) }\end{array}$ & 12 & 23 & 33 \\
$\begin{array}{l}\text { Berat Kering } \\
\text { Maksimum (gr/cm3) }\end{array}$ & 1,474 & 1,579 & 1,399 \\
\hline \multicolumn{1}{l}{ (Sumber : Hasil Laboratorium 2018) }
\end{tabular}

Pengujian pemadatan dilakukan menggunakan tiga sampel dengan kadar air berbeda yaitu $12 \%, 23 \%$, dan $33 \%$, sehingga didapatkan berat volume kering yaitu 1,474 
$\mathrm{gr} / \mathrm{cm}^{3}$ untuk kadar air $12 \%, 1,579 \mathrm{gr} / \mathrm{cm}^{3}$ untuk kadar air $23 \%$ dan $1,399 \mathrm{gr} / \mathrm{cm}^{3}$ untuk kadar air $33 \%$.

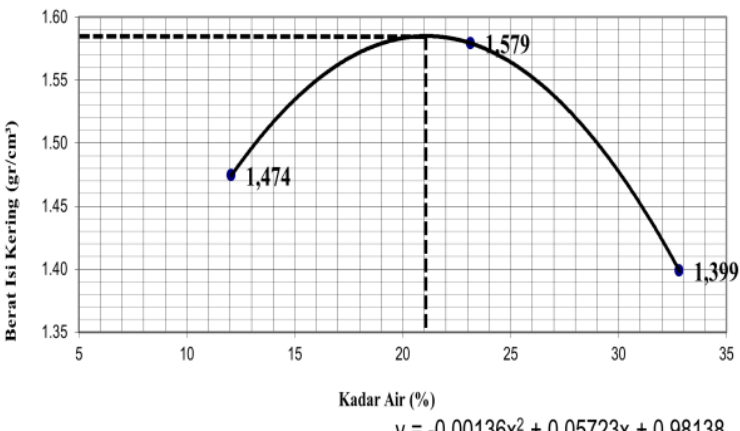

Gambar 3. Grafik Hubungan Kadar Air Optimum dan Berat Kering Maksimum

Dari hasil ketiga pengujian pemadatan tersebut kemudian diplotkan kedalam grafik hubungan sehingga membentuk garis hiperbolik. Dari kurva yang telah digambarkan didapat nilai kadar air optimum sebesar $21,04 \%$ dan kepadatan kering maksimum sebesar $1,583 \mathrm{gr} / \mathrm{cm}^{3}$. Untuk mempermudah penambahan air pada pengujian CBR Laboratorium maka nilai kadar air optimum dibulatkan menjadi $21 \%$.

\section{Pengujian CBR Laboratorium}

Tabel 6. Hasil Pengujian CBR Laboratorium Tanah Asli

\begin{tabular}{ccccc}
\hline No & Sampel & $\begin{array}{c}\text { Penetrasi } \\
\text { 0,1" }\end{array}$ & $\begin{array}{c}\text { Penetrasi } \\
0,2 "\end{array}$ & $\begin{array}{c}\text { Nilai } \\
\text { CBR } \\
\text { (\%) }\end{array}$ \\
\hline 1 & I & 16,03 & 13,98 & 15,01 \\
2 & II & 17,27 & 15,62 & 16,44 \\
3 & III & 16,03 & 15,62 & 15,83 \\
& & & Rata-rata & 15,76 \\
\hline
\end{tabular}

(Sumber : Hasil Laboratorium 2018)

Pada sampel satu diperoleh nilai CBR sebesar $15,01 \%$, sampel dua sebesar $16,44 \%$ dan sampel tiga sebesar $15,83 \%$. Sehingga nilai CBR rata-rata yang diperoleh sebesar $15,76 \%$.

\subsection{Klasifikasi Tanah Asli}

\section{Sistem Klasifikasi USCS}

Adapun hasil pengujian laboratorium menunjukan data properties tanah yang diperoleh adalah :

a. Tanah yang lolos saringan no.200 = $78,50 \%$

b. $\quad$ Batas Cair (LL) $=64,52 \%$

c. Indeks Plastisitas (PI) $=37,23 \%$

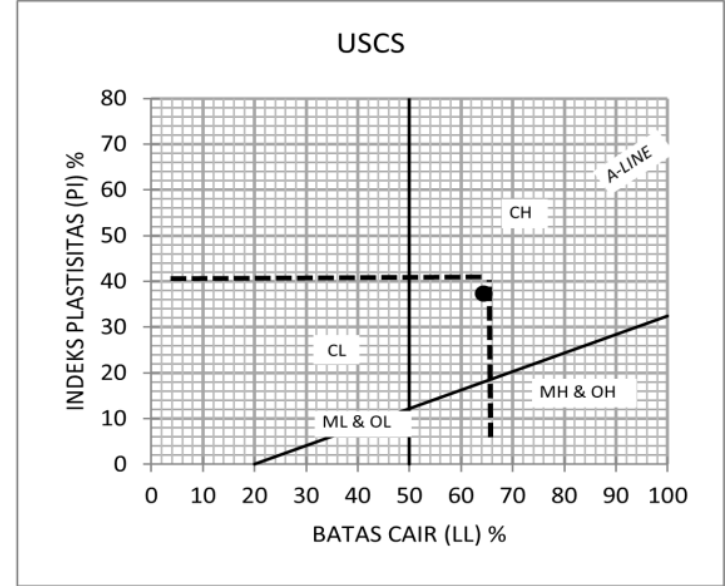

Gambar 4. Grafik Hubungan Indeks Plastisitas dan Batas Cair USCS

Dapat dilihat pada gambar 4, bahwa hasil pengeplotan menunjukan satu titik temu dari hasil batas cair (LL) dan indeks plastisitas (PI), yang mana titik temu ini menjelaskan jenis tanah yang telah diuji. Dengan merujuk pada gambar tesebut maka tanah berbutir halus pada daerah Jalan Makam, Kelurahan Malasom, Distrik Aimas, Kabupaten Sorong termasuk kedalam kelompok $\mathrm{CH}$ yaitu tanah lempung anorganik dengan plastisitas tinggi, lempung gemuk (fat clays) dengan nilai indeks plastisitas sebesar 37,23\% (plastisitas tinggi). Untuk lebih jelasnya dapat dilihat pada tabel Klasifikasi Tanah Sistem Unified.

\section{Sistem Klasifikasi AASHTO}

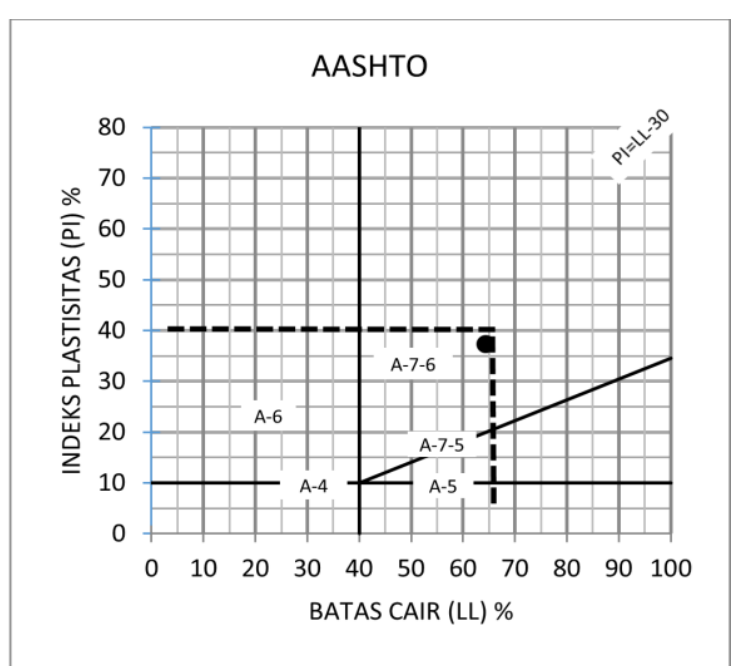

Gambar 5. Grafik Hubungan Indeks Plastisitas dan Batas Cair AASHTO

Berdasarkan gambar 5 di atas maka tanah lempung yang berasal dari daerah Jalan Makam, Kelurahan Malasom, Distrik Aimas, Kabupaten Sorong dapat dikategorikan kedalam kelompok tanah berlempung A-7-6. Untuk lebih jelasnya dapat dilihat pada tabel Klasifikasi Tanah Sistem AASHTO. 


\subsection{Pengujian Pencampuran \\ Lempung, Pasir dan Kapur}

1. Pengujian Berat Jenis (GS)

Tabel 7. Hasil Pengujian Berat Jenis Tanah Campuran dengan Pasir dan Kapur

\begin{tabular}{cccc}
\hline No & $\begin{array}{c}\text { Kadar Pasir } \\
(\%)\end{array}$ & $\begin{array}{c}\text { Kadar Kapur } \\
(\%)\end{array}$ & $\begin{array}{c}\text { Hasil } \\
(\mathrm{gr} / \mathrm{cm} 3)\end{array}$ \\
\hline 1 & 0 & 0 & 2,41 \\
2 & 20 & 4 & 2,72 \\
3 & 20 & 8 & 2,58 \\
4 & 20 & 12 & 2,55 \\
5 & 20 & 16 & 2,43 \\
\hline \multicolumn{4}{c}{ (Sumber : Hasil Laboratorium, 2018) }
\end{tabular}

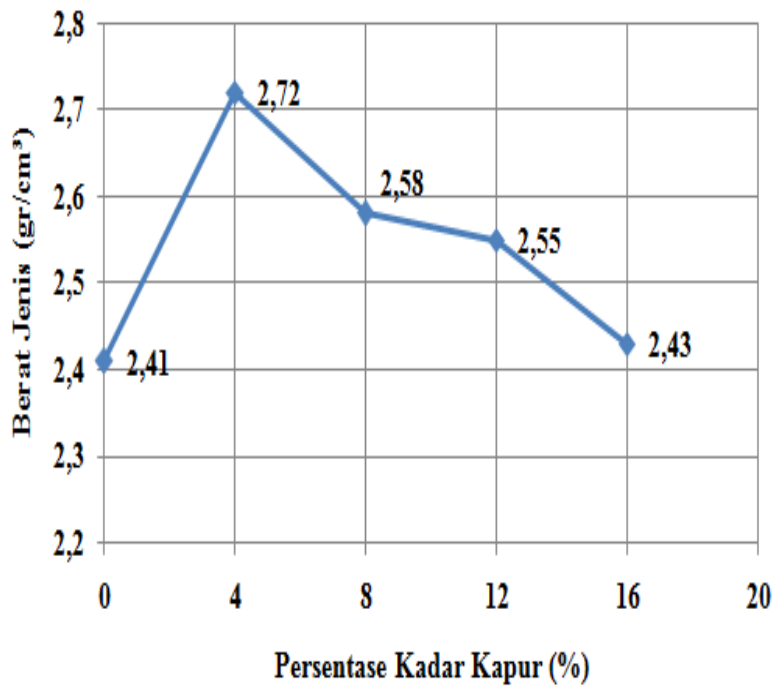

Gambar 6. Grafik Pengaruh Penambahan Pasir dan Kapur Terhadap Berat Jenis (GS)

Dari hasil pengujian berat jenis tanah campuran yang dicampur pasir dan kapur, didapatkan nilai berat jenis mengalami kenaikan tertinggi pada kadar penambahan kapur $4 \%$ sebesar $2,72 \mathrm{gr} / \mathrm{cm}^{3}$. Dapat dilihat yang awalnya berat jenis sebelum penambahan pasir dan kapur didapat $2,41 \mathrm{gr} / \mathrm{cm}^{3}$ dan setelah penambahan $4 \%$ kapur berat jenis meningkat menjadi $2,72 \mathrm{gr} / \mathrm{cm}^{3}$. Namun pada penambahan kapur $8 \%, 12 \%$, dan $16 \%$ mengalami penurunan dari penambahan kapur 4\%, dengan penambahan kapur $8 \%$ sebesar $2,58 \mathrm{gr} / \mathrm{cm}^{3}, 12 \%$ sebesar $2,55 \mathrm{gr} / \mathrm{cm}^{3}$ dan penambahan kapur $16 \%$ sebesar $2,43 \mathrm{gr} / \mathrm{cm}^{3}$.

2. Pengujian Atterberg Limit

Tabel 8. Hasil Pengujian Atterberg Limit dengan Campuran Pasir dan Kapur

\begin{tabular}{cccccc}
\hline No & $\begin{array}{c}\text { Kadar } \\
\text { Pasir } \\
(\%)\end{array}$ & $\begin{array}{c}\text { Kadar } \\
\text { Kapur } \\
(\%)\end{array}$ & $\begin{array}{c}\text { LL } \\
(\%)\end{array}$ & $\begin{array}{c}\text { PL } \\
(\%)\end{array}$ & $\begin{array}{c}\text { PI } \\
(\%)\end{array}$ \\
\hline 1 & 0 & 0 & 64,52 & 27,29 & 37,23 \\
2 & 20 & 4 & 50,70 & 23,87 & 26,82 \\
\hline
\end{tabular}

\begin{tabular}{cccccc}
\hline 3 & 20 & 8 & 49,06 & 23,26 & 25,80 \\
4 & 20 & 12 & 48,02 & 22,36 & 25,65 \\
5 & 20 & 16 & 46,4 & 21,32 & 25,08 \\
\hline \multicolumn{7}{c}{ (Sumber : Hasil Laboratorium, 2018) }
\end{tabular}

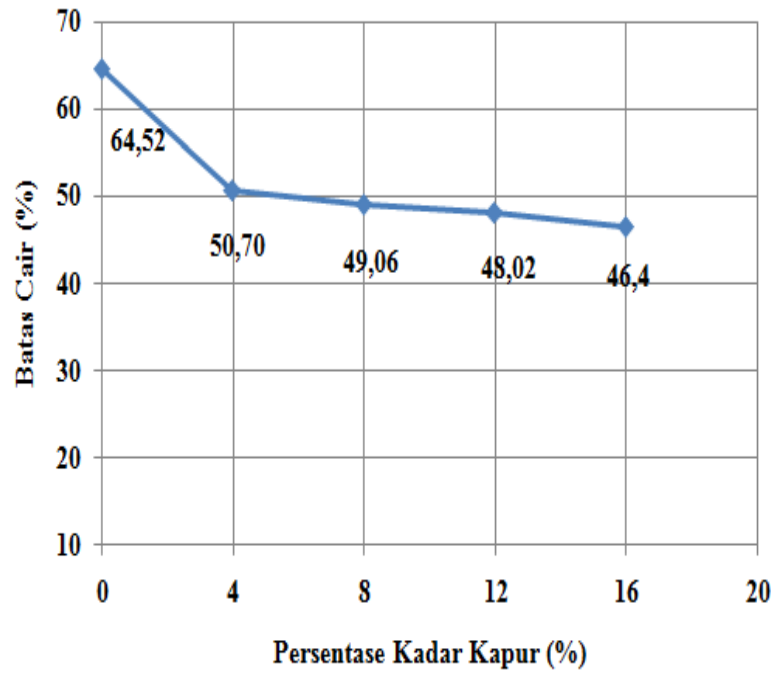

Gambar 7. Grafik Pengaruh Penambahan Pasir dan Kapur Terhadap Batas Cair (LL)

Dari gambar 7, dengan bertambahnya persentase kadar kapur dapat dilihat nilai batas cair (LL) mengalami penurunan dari batas cair (LL) tanah asli. Yang awalnya nilai batas cair tanah asli sebesar $64,52 \%$ turun mencapai $46,4 \%$ pada penambahan persentase kadar kapur $16 \%$.

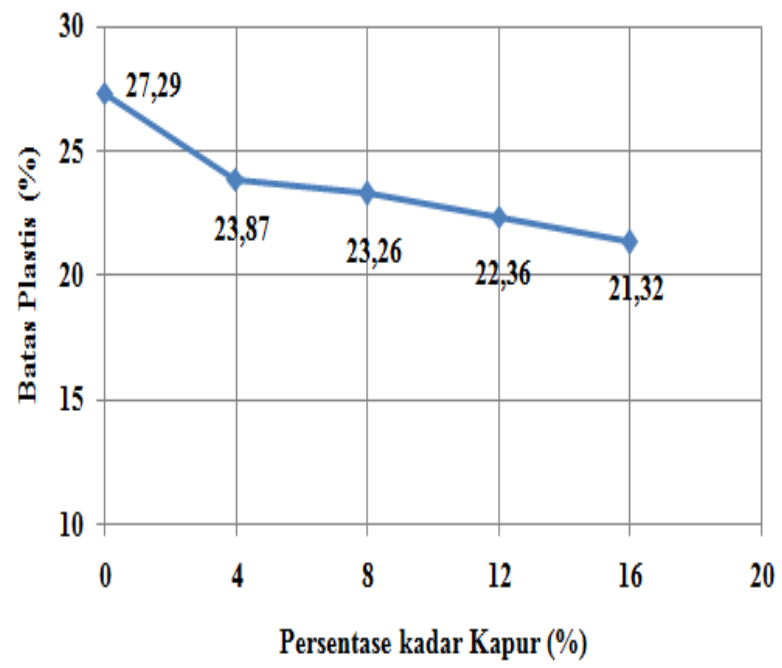

Gambar 8. Grafik Pengaruh Penambahan Pasir dan Kapur Terhadap Batas Plastis (PL)

Dari gambar 8, sama halnya dengan batas cair (LL), nilai batas plastis (PL) mengalami penurunan dari nilai batas plastis (PL) tanah asli sebesar $27,29 \%$ menjadi $21,32 \%$ pada penambahan persentase kadar kapur $16 \%$. 


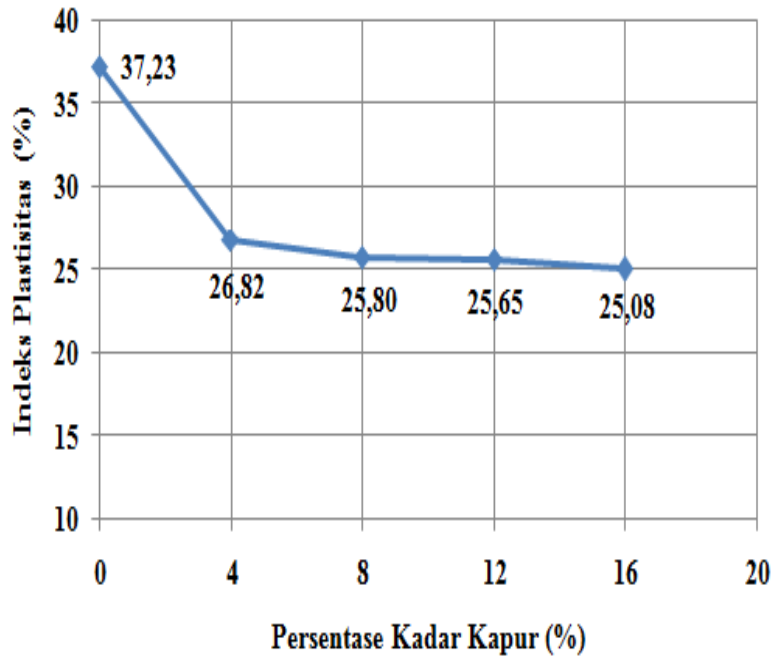

Gambar 9. Grafik Pengaruh Penambahan Pasir dan Kapur Terhadap Indeks Plastisitas (PI)

Dari gambar 9, hasil pengujian batas cair (LL) dan batas plastis (PL) mengalami penurunan maka indeks plastis (PI) ikut menurun dari setiap penambahan persentase kadar kapur. Hal ini menunjukan dengan penambahan pasir dan kapur dapat mengurangi keplastisan tanah.

3. Pengujian CBR Laboratorium

Hasil pengujian CBR Laboratorium (unsoaked) dengan campuran kapur dapat dilihat pada tabel 9 sampai tabel 13 .

Tabel 9. Hasil Pengujian CBR (unsoaked) dengan Campuran Pasir $20 \%$ dan Kapur 4\%

\begin{tabular}{ccccc}
\hline No & Sampel & $\begin{array}{c}\text { Penetrasi } \\
\text { 0,1" }\end{array}$ & $\begin{array}{c}\text { Penetrasi } \\
0,2 "\end{array}$ & $\begin{array}{c}\text { Nilai } \\
\text { CBR } \\
(\%)\end{array}$ \\
\hline 1 & I & 17,27 & 16,44 & 16,86 \\
2 & II & 17,27 & 15,62 & 16,44 \\
3 & III & 17,27 & 15,62 & 16,44 \\
& & & Rata-rata & 16,58 \\
\hline
\end{tabular}

(Sumber : Hasil Laboratorium, 2018)

Tabel 10. Hasil Pengujian CBR (unsoaked) dengan Campuran Pasir $20 \%$ dan Kapur 8\%

\begin{tabular}{ccccc}
\hline No & Sampel & $\begin{array}{c}\text { Penetrasi } \\
0,1 "\end{array}$ & $\begin{array}{c}\text { Penetrasi } \\
0,2 "\end{array}$ & $\begin{array}{c}\text { Nilai } \\
\text { CBR } \\
(\%)\end{array}$ \\
\hline 1 & I & 12,33 & 12,33 & 12,33 \\
2 & II & 13,57 & 12,33 & 12,95 \\
3 & III & 12,33 & 12,33 & 12,33 \\
& & & Rata-rata & 12,54 \\
\hline
\end{tabular}

(Sumber : Hasil Laboratorium, 2018)

Tabel 11. Hasil Pengujian CBR (unsoaked) dengan Campuran Pasir $20 \%$ dan Kapur 12\% $\begin{array}{llll}\text { No Sampel Penetrasi Penetrasi } & \text { Nilai } \\ \text { CBR }\end{array}$

\begin{tabular}{ccccc} 
& & $0,1^{\prime \prime}$ & $0,2^{\prime \prime}$ & $(\%)$ \\
\hline 1 & I & 9,87 & 9,87 & 9,87 \\
2 & II & 8,63 & 8,22 & 8,43 \\
3 & III & 8,63 & 8,22 & 8,43 \\
& & & Rata-rata & 8,91 \\
\hline
\end{tabular}

(Sumber : Hasil Laboratorium, 2018)

Tabel 12. Hasil Pengujian CBR (unsoaked) dengan Campuran Pasir $20 \%$ dan Kapur 16\%

\begin{tabular}{ccccc}
\hline No & Sampel & $\begin{array}{c}\text { Penetrasi } \\
0,1 "\end{array}$ & $\begin{array}{c}\text { Penetrasi } \\
0,2^{\prime \prime}\end{array}$ & $\begin{array}{c}\text { Nilai } \\
\text { CBR } \\
(\%)\end{array}$ \\
\hline 1 & I & 7,4 & 7,4 & 7,40 \\
2 & II & 8,63 & 8,22 & 8,43 \\
3 & III & 8,63 & 7,4 & 8,02 \\
& & & Rata-rata & 7,95 \\
\hline
\end{tabular}

(Sumber : Hasil Laboratorium, 2018)

Tabel 13. Rekapitulasi Hasil Pengujian CBR Laboratorium Tanah asli dengan Campuran Pasir dan Kapur

\begin{tabular}{cccc}
\hline No & $\begin{array}{c}\text { Kadar Pasir } \\
(\%)\end{array}$ & $\begin{array}{c}\text { Kadar Kapur } \\
(\%)\end{array}$ & $\begin{array}{c}\text { CBR } \\
(\%)\end{array}$ \\
\hline 1 & 0 & 0 & 15,76 \\
2 & 20 & 4 & 16,58 \\
3 & 20 & 8 & 12,54 \\
4 & 20 & 12 & 8,91 \\
5 & 20 & 16 & 7,95 \\
\hline \multicolumn{4}{c}{ (Sumber : Hasil Laboratorium, 2018) }
\end{tabular}

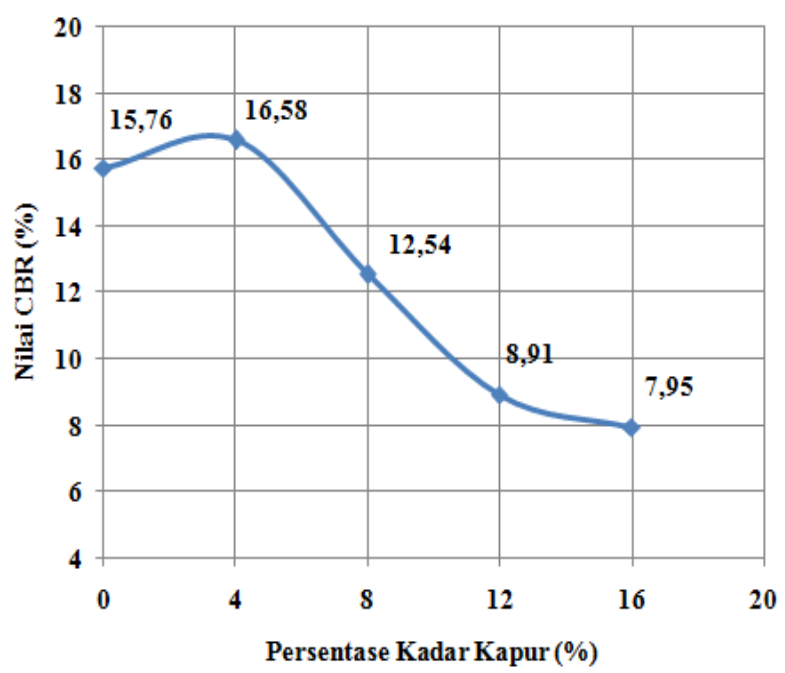

Gambar 10. Grafik Pengaruh Penambahan Pasir dan Kapur Terhadap Nilai CBR Laboratorium

Dari gambar dan tabel hasil pengujian CBR Laboratorium, dapat dilihat dengan penambahan pasir $20 \%+$ kapur $4 \%, 8 \%, 12 \%$ dan $16 \%$ nilai CBR naik dari tanah asli hanya pada persentase kadar pasir $20 \%$ + kapur $4 \%$ sebesar $16,58 \%$. Nilai CBR mengalami penurunan pada 
penambahan pasir $20 \%+$ kapur $8 \%, 12 \%$ dan $16 \%$.

\section{Kesimpulan}

Berdasarkan hasil pengujian dan pembahasan yang telah dilakukan terhadap sampel tanah lempung yang distabilisasi menggunakan pasir dan kapur, maka diperoleh kesimpulan dengan penambahan pasir $20 \%+$ kapur $4 \%, 8 \%, 12 \%$ dan $16 \%$ nilai CBR naik dari tanah asli pada penambahan pasir $20 \%$ + kapur $4 \%$ sebesar $16,58 \%$. Nilai CBR mengalami penurunan pada penambahan pasir $20 \%+$ kapur $8 \%$ sebesar $12,54 \%, 12 \%$ sebesar $8,91 \%$ dan $16 \%$ sebesar $7,95 \%$.

\section{Referensi}

Anggreni, N, (2017). Uji Eksperimental Stabilisasi Tanah Lempung Dengan Menggunakan Pasir Terhadap Tingkat Kepadatan Tanah, Universitas Muhammadiyah Sorong, Papua Barat

Arifin, Y.F, Markawie (2013). Stabilisasi Tanah Lempung Lunak dengan Kapur Pada Kondisi Kadar Air Lapangan. Universitas Lambung Mangkurat. INFO Teknik Volume 14 No. 1.

Asfian, A.I, (2017). Stabilisasi Tanah Kabupaten Sorong dengan Kapur sebagai Lapisan Perkerasan, Universitas Muhammadiyah Sorong, Papua Barat.

Hardiyatmo, H.C, (2010). Stabilisasi Tanah Untuk Perkerasan Jalan, Universitas Gadjah Mada, Yogyakarta

Pangestu, D.A, (2013). Studi Daya Dukung Stabilisasi Tanah Lempung Lunak Menggunakan Campuran Abu Ampas Tebu Dan Abu Sekam Padi Dengan Semen, Universitas Lampung. Bandar Lampung

Prihatini, R, (2013). Pengaruh Perendaman Terhadap Stabilisasi Tanah Lempung Lunak Menggunakan Abu Ampas Tebu (Bagasse Ash), Universitas Lampung, Bandar Lampung.

Rahmayasa, D, (2013). Studi Daya Dukung Stabilisasi Tanah Lempung Lunak Menggunakan Campuran Abu Ampas Tebu Dan Semen, Universitas Lampung. Bandar Lampung

Soedarmo, G.D \& Purnomo, E, (1997). Mekanika Tanah 1, Yogyakarta

SNI Revisi 03 - 1965 - 1990 ke 1965 - 2008 Metode Pengujian Kadar Air

SNI Revisi dari 03 - 1967 - 1990 ke 1967 - 2008 Metode Pengujian Batas Cair Dengan Alat Casagrande
SNI Revisi dari 03 - 1966 - 1990 ke 1966 - 2008 Metode Pengujian Batas Plastis

SNI Revisi dari 03 - 1964 - 1990 ke 1964 - 2008 Metode Pengujian Berat Jenis Tanah

SNI Revisi dari 03 - 3423 - 1994 ke 3423 - 2008 Metode Pengujian Analisis Ukuran Butiran Tanah Dengan Alat Hidrometer

SNI Revisi dari 03 - 1743 - 1989 ke $1742-2008$ Metode Pengujian Kepadatan Berat Untuk Tanah

SNI 174-2012 Revisi dari SNI 03-1744-1989 Metode Pengujian CBR Laboratorium

Sutarman, E, (2013). Konsep \& Aplikasi Mekanika Tanah, Yogyakarta

Wesley, L.D, (2017). Mekanika Tanah Edisi Baru, Yogyakarta

Yulianti, D, /D11108297. Klasifikasi Tanah Berdasarkan CBR. Retrived September 18, 2017 , from https://kupdf.net/download/klasifikasi-tanahberdasarkancbr_59beae4308bbc5530f686ed5_pdf. 